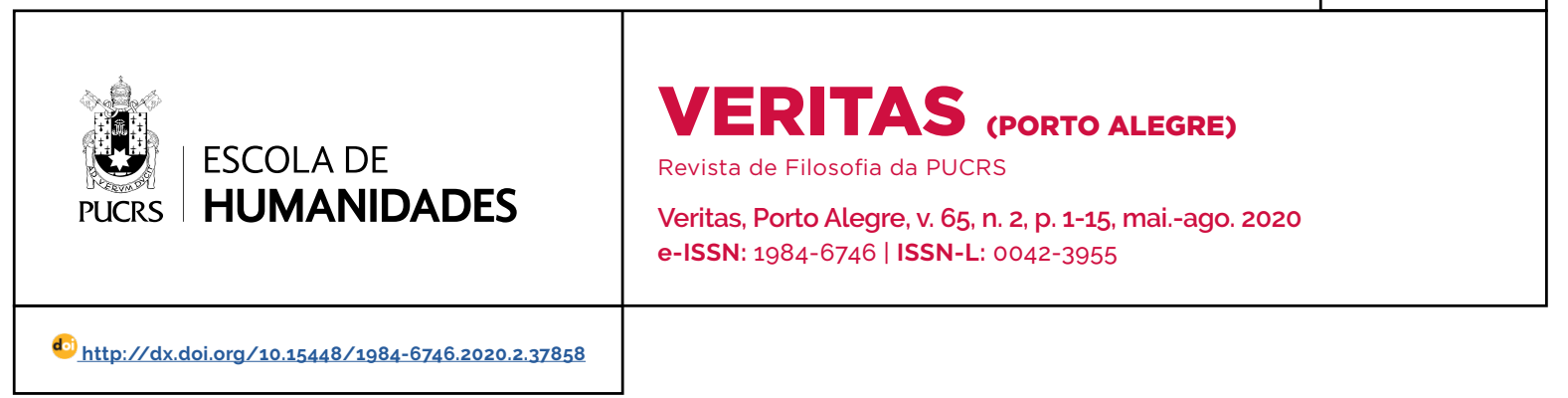

SEÇÃO: ESTÉTICA

\title{
Fantasmaterialidade: o subsolo estético da Crítica da razão negra
}

\author{
Phantomateriality: the aesthetic subsoil of Critique of black reason \\ Fantasmaterialidad: el subsuelo estético de la Critica de la razón negra
}

\section{Alexandre Costi Pandolfo $^{1}$ \\ orcid.org/0000-0001-9415-7276 alexandrecostipandolfo@gmail.com}

Recebido em: 28 abr. 2020. Aprovado em: 9 mai. 2020. Publicado em: 28 jul. 2020.

\section{(c) (1)}

Artigo está licenciado sob forma de uma licença Creative Commons Atribuicão 4.0 Internacional.
Resumo: Este ensaio procura tecer considerações estéticas, filosóficas e políticas a respeito da imagem do "subsolo", indicada por Achille Mbembe no seu livro Crítica da razão negra. Partindo dessa imagem, o ensaio aponta para outras, principalmente, o fantasma e o espectro, com as quais forma uma constelação. Devido a sua forma, este ensaio torna-se uma montagem, para a qual contribuem fragmentos de obras de Lima Barreto e de Carolina Maria de Jesus, procurando dialogar com as proposições de Mbembe e levar a cabo uma crítica da ontologia fundamental e as suas consequências genocidas.

Palavras-chave: Estética. Literatura. Fantasma. Colonialismo; Racismo.

Abstract: This essay intents to weave aesthetical, philosophical and political considerations about the image of the "subsoil", mention by Achille Mbembe in his book "Critique of black reason". Starting from this image, the essay points to others, mainly, the phantom and the spectrum, with which it forms a constellation. Because of its form, this essay becomes a montage, for which contribute fragments of the works of Lima Barreto and Carolina Maria de Jesus, pieces that seek to dialogue with Mbembe's proposals and carry out a critic of fundamental ontology and its genocidal threats.

Keywords: Aesthetics. Literature. Phantom. Colonialism. Racism.

Resumen: Este ensayo busca tejer consideraciones estéticas, filosóficas y políticas con respecto a la imagen del "subsuelo", indicada por Achille Mbembe en su libro "Crítica de la razón negra". A partir de esta imagen, el ensayo apunta para otras, principalmente, el fantasma y lo espectro, con las que forma una constelación. Debido a su forma, este ensayo puede ser entendido como un montaje, a lo cual contribuyen fragmentos de obras de Lima Barreto y de Carolina María de Jesús, recortes que buscan dialogar con las propuestas de Mbembe y llevar a cabo una critica de la ontología fundamental y sus amenazas genocidas.

Palabras clave: Estética. Literatura. Fantasma. Colonialismo. Racismo.

"...c'est de la ruine qu'il s'agit - le temps de la ruine et de la destruction".2 lé da ruina que se trata - o tempo da ruina e da destruição]

Intento e trato de traçar as agruras do termo "subsolo" utilizado, especialmente, por Achille Mbembe como uma espécie de imagem dialética para lidar com o que ele chama de razão negra, a racionalidade que não apenas permite, mas fabrica a escravidão, um corpo-coisa-objeto-sujeito-racial, contra a qual Mbembe escreveu, justamente, a sua Critique de la raison nègre. O presente ensaio é uma tentativa de organizar um punhado de ideias não idênticas, filosóficas e literárias, 
estéticas e políticas, partindo disso: "le sous-sol de tout ce livre"3, o subsolo, o porão de todo o livro - o capítulo intitulado "Réquiem para o escravo". Capitulo a mais de uma longa história inacabada de assassinatos, massacres, explorações e torturas, a respeito dos quais Mbembe, procurando lê-los, procurando vê-los, ler tais acontecimentos e radicalmente criticá-los, ver e devolver o agulhão de uma sua inteligibilidade histórica, para isso, recorre ao que ele chama de "écriture figurale", a "escrita figural" - a literatura -, porque, "pour bien comprendre le statut de l'esclave nègre à l'époque du premier capitalisme, il importe de revenir à la figure du revenant"4 - revenir à la figure du revenant - quer dizer. para compreender bem o estatuto do escravo negro na época do primeiro capitalismo é importante retornar à figura do espectro. Le revenant. O retornante. O escravo negro, espectro da modernidade, precisamos vê-lo, diz Mbembe, por meio da experiência literária, lê-lo na forma de uma experiência da imagem, da linguagem, isso aí não aí, fantasma. O que me interessa sobremaneira, porque se trata de percorrer os caminhos, os trânsitos da expressão, da figuração e da representação, percorrer as vias imiscuidas da forma e do conteúdo, percorrer os desvãos, as estrias, as agruras da degradação, da maldição, da abjeção, em sentido estético e filosófico político - procurar os rastros de inteligibilidade de uma situação real atravessada por imagens fatos feitos discordâncias com o real. Um emaranhado estético, portanto, cujas consequências filosóficas são práticas, a saber, políticas e éticas. Ora, "pour bien comprendre", para bem compreender, para o bom entendimento desse tema, para bem entender essa situação, para que se compreenda bem isso, para que tu, a bem dizer, compreendas bem o estatuto, o material legal ilegal, a situação do escravo ontem e hoje, Mbembe não parece se referir à compreensão e à adequação senão num sentido muito debilitado, enfraquecido, ensombrecido, escombrecido, eu diria, segundo o qual, apenas em suas últimas forças nos deparamos com o sopro de uma racionalidade crítica fora de todo domínio ontológico de implementação racional da barbárie - encontrando na forma transitória de um conteúdo o recurso às imagens de linguagem, corpos de linguagem, corpos fantasmáticos ali evocados como instantes de elucidação. Importa ressaltar, então, que a filosofia política de Mbembe clama pela literatura quando trata do devir negro da civilização ocidental. Clamar, chamar, nomear, pois, rogar, bradar. E a ficção, outramente que ser aí, criptografa-se, encripta-se, enigma-se contra as mil artimanhas para a sua adequada compreensão. Então, "adequar" e "compreender" resguardam, ambos em seus termos, as suas facetas em torso, torcidas, sinuosas, no esquema de Mbembe, dada a importância - cada vez maior e sempre impossivel possivel - da situação da compreensão tornada compressão, supressão, captura e predação, apagamento, ao longo da história do imperialismo ocidental colonial capital escravagista-escravocrata. E ao adentrarmos o subsolo, o porão, a cava, a vala dessa história nos encontramos fatidicamanente com os outros, os nossos, seus espectros. Os negros. Mas não apenas literariamente falando. A realidade que evoca um estilo escritural, a realidade de sujeito plástico e o conceito de realismo tornam-se também subvertidos nesse âmbito. Trata-se de uma trama de anéis entrelaçados oscilando sem cessar - "un lacis complexe de boucles entrecroisées, oscillant sans cesse entre le vertigineux, la dissolution et l'éparpillement, et dont les arêtes et les lignes se rejoignent au point de fuite"5 - entre vertigem, dissolução e dispersão, cujas arestas, as bordas, margens e linhas disjuntas se rejuntam, antefinalmente, encontram-se, apenas para cruzarem-se no ponto de fuga. E, pois, o ponto de fuga se torna um ponto de abertura para -. Para o outro. Abertura de si. O brumoso estado "au-delà de tout présent vivant, dans ce qui disjointe le présent vivant" ${ }^{\prime}$, quer dizer, o 
brumoso estado para além de todo presente vivo, a conjuntura que disjunta, que desajunta o presente vivo, isso me toca e me comove e me exige lembrar, pois, esse livro de Jacques Derrida, Spectres de Marx, especialmente no que concerne à reflexão especular - uma reflexividade literária, plástica, duplicada, multiplicada que "doit donc excéder toute présence comme présence à soi"7, que deve, portanto, exceder toda a presença como presença a si mesma "devant les fantômes de ceux qui ne sont pas encore nés ou qui sont déjà morts"8 - diante dos fantasmas daqueles que ainda não são, que ainda não nasceram, ou até, talvez, daqueles que nasceram e, contudo, não são, ou não foram, diante daqueles que agora já não são mais porque estão mortos e que talvez um dia tenham sido ou não - diante daqueles não aí, portanto, volta-se o torso do porvir. Que associo com o aforisma de Walter Benjamin, em Einbahnstrasse, na coleção das "Antiquitäten", chamado "Torso", que diz respeito a uma bela estátua, uma figura que o transporte quebrou todos os seus membros "und die nun nichts als den kostbaren Block abgibt, aus dem er das Bild seiner Zukunft zu hauen hat"9 - e que tem para oferecer agora nada mais que um precioso bloco para esculpir nele a imagem do futuro. Tratando, assim, de reelaborar, remontar, no sentido cinematográfico, o tempo disjunto do presente ante à inadequação a si e ao outro, o pensamento por imagens ousa transpor a crise e a crítica para além do presente do indicativo do verbo ser, para além das tratativas ontológicas para o acomodamento da consciência da debilidade, das tratativas históricas para o anestesiamento geral dessa consciência na comunicação do sentido da debilidade no conhecimento da fragilidade e na adequação à fugacidade aí - como se não, senão ser. Então, uma tal ousadia filosófico-política, esculpir a imagem do ainda não, na contramão de toda ontologia, de todo fundamento no ser da existência, jamais reconduz de volta o talho, a letra ou a imagem à existência de antemão apropriada, retroapropriada ao sendo de um seu constante brilhar, jamais reconduz ao aparecer do que é como é porque é a tradição do aniquilamento do outro, o ser sempre aí, preexistente. ${ }^{10}$ Das Ereignis fatídico, aqui não. - O acontecimento apropriante de tudo o que é para ser, encontra, pois, o seu limite filosófico, o seu limite ético. Nem clareira, nem bosque, correnteza ou ninho logram, então, nesse âmbito, nesse abismo, velar pelo ser, pela presença e pela identidade a si do ser. "The time is out of joint" - enunciara Hamlet - e enfatiza, sobremaneira, Derrida ${ }^{11}$, opondo-se, por esse lance de corpo e de linguagem, por esse movimento de cena, ao jogo ontológico ao qual se encontra imbricado o todo de sentido do estado lamaçal das coisas em direção à morte. Há algo de podre aí, aqui, obnubilado pelo ser. Então, alerta Derrida, nesse âmbito soprando ao lado de Mbembe: trata-se de lidar com a chance de levar a vida para além da vida presente, "au-delà de la vie présente ou de son être-là effectif, de son effectivité empirique ou ontologique"12, para além da ontologia e de sua efetividade empírica, dos poderes governamentais e administrativos e juridicos do estar-presente efetivo em direção à morte, para além desta, volver, virar à sobrevida, quer dizer, "non pas vers la mort mais vers une sur-vie"13, rumo a uma pós-morte, um regressar fantasmático à pós-vida, após-vida-não-vivida, uma vida póstuma, Nachleben

\footnotetext{
7 DERRIDA, Jacques. Spectres de Marx. L'État de la dette, le travail du deuil et la nouvelle Internationale. Paris: Galilée, 1993. p. 16. 8 DERRIDA, Jacques. Spectres de Marx. L'État de la dette, le travail du deuil et la nouvelle Internationale. Paris: Galilée, 1993. p. 16. 9 BENJAMIN, Walter. Einbahnstrasse. Berlin: Ernst Rowohlt Verlag, 1928. p. 46. Conferir o aforisma completo: "TORSO. Nur wer die eigene Vergangenheit als Ausgeburt des Zwanges und der Not zu betrachten wüßte, der wäre fähig, sie in jeder Gegenwart aufs höchste für sich wert zu machen. Denn was einer lebte, ist bestenfalls der schönen Figur vergleichbar, der auf Transporten alle Glieder abgeschlagen wurden, und die nun nichts als den kostbaren Block abgibt, aus dem er das Bild seiner Zukunft zu hauen hat".

10 HEIDEGGER, M. A origem da obra de arte. Trad. Idalina Azevedo e Manuel de Castro. São Paulo: Edições 70, 2010. p. 87. Edição bilingue. Conferir trecho em língua alemã, o sumo ontológico da obra de arte: "Dieses Seiende tritt in die Unverborgenheit seines Seins heraus. l... Im Werk ist, wenn hier eine Eröffnung des Seienden geschieht in das, was und wie es ist, ein Geschehen der Wahrheit am Werk. Im Werk der Kunst hat sich die Wahrheit des Seienden ins Werk gesetzt. [...] Das Sein des Seienden kommt in das Ständige seines Scheinens. So wäre denn das Wesen der Kunst dieses: das Sich-ins-Werk-Setzen der Wahrheit des Seienden" (2010, p. 86).

11 DERRIDA, Jacques. Spectres de Marx. L'État de la dette, le travail du deuil et la nouvelle Internationale. Paris: Galilée, 1993. p. 16

12 DERRIDA, Jacques. Spectres de Marx. L'État de la dette, le travail du deuil et la nouvelle Internationale. Paris: Galilée, 1993. p. 17.

13 DERRIDA, Jacques. Spectres de Marx. L'État de la dette, le travail du deuil et la nouvelle Internationale. Paris: Galilée, 1993. p. 17.
} 
(como também chamaram Warburg e Benjamin), na qual "des traces et des traces de traces [...] vient d'avance disjoindre ou désajuster l'identité à soi du présent vivant comme de toute effectivité"14 - a saber, para além da vida não-vivida de uma existência totalmente avassalada, execrada e consumada, diante da qual os traços e os traços dos traços, os rastros e os rasgos dos rastros, os vestígios e traços dos vestígios vêm do porvir irreversivelmente desajustado à identidade a si do presente aparentemente vivo; terão vindo como que do futuro anterior, do futuro do pretérito, abrir a passagem ao ausente, ao fantasma, oferecer o tempo ao rastro que a escrita ficcional abre - às possibilidades de sentidos não previamente dadas - disjuntar, desajustar a aparência da identidade, a aparência do presente existente, vivo não-vivo e toda a sua efetividade.

Cito Machado de Assis, em Memórias póstumas de Brás Cubas:

- Chama-me Natureza ou Pandora; sou tua mãe e tua inimiga.

Ao ouvir esta última palavra, recuei um pouco, tomado de susto. A figura soltou uma gargalhada, que produziu em torno de nós o efeito de um tufão; as plantas torceram-se e um longo gemido quebrou a mudez das coisas externas.

- Não te assustes, disse ela, minha inimizade não mata; é sobretudo pela vida que se afirma. Vives: não quero outro flagelo.

- Vivo? perguntei eu, enterrando as unhas nas mãos, como para certificar-me da existência.

- Sim, verme, tu vives. Não receies perder esse andrajo que é teu orgulho; provarás ainda, por algumas horas, o pão da dor e o vinho da miséria. Vives: agora mesmo que ensandeceste, vives; e se a tua consciência reouver um instante de sagacidade, tu dirás que queres viver. ${ }^{15}$
Aqueles que, como eu, dedicam-se ao estudo do estatuto das aparências na literatura brasileira, ao se depararem com o tema estético e filosófico-político do subsolo, disjuntado de um espaço-tempo presente a si mesmo, póstumo, do tema da vida póstuma, do futuro anterior não no retrovisor e das circunstâncias criticas as mais radicais que o envolvem, talvez, imediatamente ou involuntariamente se remetam ao romance Memórias póstumas de Brás Cubas, de Machado de Assis. A isso procuro colacionar, colecionar, associar algumas imagens outras, lampejos provenientes, especialmente, de O cemitério dos vivos e Diário do hospicio, de Lima Barreto, além do Quarto de despejo, de Carolina Maria de Jesus. Ora, Mbembe, na evocação, escovação que faz no subsolo do seu livro, trabalha com outras três ficções: La vie et demie, de Sony Labou Tansi, The palm wine drinkard e My life in the Bush of ghosts, de Amos Tutuola. Trato aqui, então, de oferecer uma espécie de diálogo com as imagens já apresentadas pelo filósofo. Imagens essas entendidas como "dialéticas", no sentido crítico-cristal apontado pela estética de Benjamin. Porque há muitas vias que levam ao subsolo da crítica da razão negra, ao adentrarmos o qual, encontraremos não apenas as literaturas, as ficções apontadas expressamente por Mbembe, mas também muitas outras, globalmente falando, mesmo fora do domínio próprio do autor, a espera de se tonarem evidentes. Então, parece nebuloso pensar que já o dentro e o fora dessas vias jamais serão ou estarão plenamente definidos, circunscritos aí. E as evocações literárias no circuito de uma constelação teórica devem nos deixar

\footnotetext{
14 DERRIDA, Jacques. Spectres de Marx. L'État de la dette, le travail du deuil et la nouvelle Internationale. Paris: Galilée, 1993. p. 17. Conferir, a respeito do pensamento de Derrida referente aos espectros, o texto de Moysés Pinto Neto, A estranha instituição da literatura no multiverso dos espectros, de onde retiro as seguintes considerações, cujas implicações são cruciais para a inteligibilidade da problemática que procuro traçar aqui: "A ontologia, ao afirmar o primado do ser e o dualismo ôntico/ontológico, seria mais um capítulo da metafísica enquanto clausura. Seria preciso ir além da ontologia, pensando uma dyferença que nunca se faz inteiramente presente, pois se dá em forma de rastro ou grafema, para então pensar essa escritura como uma abertura" (p. 118). Nesse sentido, para Derrida, "A chave para compreensão da espectrologia é a psicanálise [...]. Psicanálise como matriz teórica da espectrologia" (p. 120) devido ao "modelo econômico do inconsciente, fundado numa matriz energética e cujo conteúdo é fantasmático (p. 124), quer dizer, "a intimidade da psicanálise com os fantasmas nasce da decisão metodológica de Sigmund Freud [...] que reconhece a fantasia como elemento com seu estatuto próprio de realidade psiquica" (p. 124). Além disso, "a literatura habita o mesmo espaço espectral que o sonho. A ficção [torna-se] aquilo que não cansa de lembrar as infinitas variações do possivel", cujas consequências são epistemológicas e políticas, motivo pelo qual, "Derrida vinculava a 'estranha instituição da literatura' - lembrando [com isso] do papel do estranho na psicanálise -, ao papel de condição da democracia" (p. 125). Essa implicação estético-política é crucial para os apontamentos que quero fazer aqui. Devo lembrar também o que escreveu Joel Birman, em Freud e a filosofia, a saber, "enunciar que a verdade do acontecimento se ordena na realidade psíquica e não na [realidade] material é formular ainda que as certezas da individualidade seriam forjadas por fantasmas" (p. 36), assim, "seriam os fantasmas que alinhavariam o sentido dos acontecimentos, direcionando as cenas psiquicas. Por isso mesmo, as leituras de Derrida e Lacan, centradas respectivamente na escrita e na fala como materialidades da linguagem, puderam se reencontrar com o discurso freudiano" (p. 37).

15 ASSIS, Joaquim Maria Machado de. Memórias póstumas de Brás Cubas. Porto Alegre: L\&PM Pocket, 1997. p. 26.
} 
ainda mais atentos ao fato de que as imagens criticas trazidas por Mbembe estabelecem diálogos profundos com alguns dos mais importantes pensadores e críticos do que se convencionou chamar de modernidade e pós-modernidade no mundo ocidental, como, por exemplo, Deleuze, Derrida e Lacan, dentre muitos outros como Cesaire, Fanon, Freud, Benjamin, Bataille, Foucault, Heidegger, Hegel, Kant, e ainda outros, vivos, Gilroy, Buck-Morss, Badiou, todos os quais cintilam na composição textual de Mbembe e por mais de um ângulo se deixam atravessar pela luz, rondando a forma e o conteúdo da inteligibilidade das condições sistemáticas às quais os escravos negros foram submetidos, a escravidão cuja tendência à universalização constitui aujourd'hui, agora, pois, senão a norma, pelo menos a parte que cabe a todas as humanidades subalternas, o quinhão desse latifúndio, o lote, como escreveu Mbembe, "les risques systémiques auxquels seuls les esclaves nègres furent exposés au moment du premier capitalisme constituent désormais sinon la norme, du moins le lot de toutes les humanités subalternes"16, quer dizer que o devir negro do mundo tem um significado universal, não apenas local; a fungibilidade, a descartabilidade ou intercambialidade universal do negro e sua solubilidade no mercado da vida e da morte - "c'est cette fongibilité nouvelle, cette solubilité, son institutionnalisation en tant que nouvelle norme d'existence et sa généralisation à l'ensemble de la planète que nous appelons le devenir-nègre $d u$ monde"17 - alcança todas as subalternidades (inclusive as não humanas), o devir negro do mundo vindo a ser a norma da existência planeta afora alcança o limiar, a bruma, desde onde se deixa ver, própria-impropriamente, sentir, ali está-não-está "le cachot des apparences"18, o calabouço das aparências, uma cova, um tal estado úmido de fato brumoso, articulado micro e macroscopi- camente, húmus de onde despertam sentidos múltiplos que há muito deixaram de ser evidentes e que, inclusive, desde as ruinas sob ruinas, despertam em rearticulações de traços, brumas de traços póstumos os fantasmas das suas articulações prévias. Mas eu gostaria de chamar a atenção para um fora dentro da circunscrição fantasmática do subsolo da Critique de la raison nègre, tratando-se de uma situação a respeito da qual escreveu Mbembe num outro livro, Sair da grande noite, a situação da poesia e da memória, do canto da palavra na noite do mundo, que não poderia mais meramente celebrar a beleza do mal, ou talvez a sua banalidade, tal como Heidegger fizera com a arregimentação do espírito junto à mitologia e à nostalgia da origem, bem como junto ao encantamento da existência, porque torna-se agora "necessário resistir à [essa] cumplicidade por encantamento e saber qual é a sua filiação no 'destino da noite do mundo'". ${ }^{19}$ Assim, nesse ensaio, a partir da imagem do crânio de um morto, Mbembe articula memórias que remontam à sua infância e à trajetória do seu pensamento, articula os motivos pelos quais ele pensa o que pensa e procura refletir sobre isso, à sombra de regiões muitas vezes desprovidas de nomes próprios, como diz, nas quais o rufar dos tambores ancestrais anunciam passagens de um mundo para o outro. Mbembe evoca e invoca em suas lembranças as "histórias que se contavam sobre este ou aquele cuja sombra, num dia deslumbrante, fora avistada num campo onde essa mesma pessoa costumava trabalhar [antes de morrer]"20, e a isso se mistura a memória do seu tio assassinado pelo terror do Estado capital colonial, cujo crânio faz figura, ossifica, por assim dizer, a aparência dos pesares, o "crânio de um parente morto na cabeceira do Estado"21, como ele escreve; o nome proibido de seu tio, impronunciável mesmo despois da "independência", nome disjunto à aparência de liberta-

\footnotetext{
MBEMBE, A. Critique de la raison nègre. Paris: La Découverte, 2013. p. 14

MBEMBE, A. Critique de la raison nègre. Paris: La Découverte, 2013. p. 17, 248

MBEMBE, A. Critique de la raison nègre. Paris: La Découverte, 2013. p. 11

MBEMBE, Achille. Sair da grande noite. Ensaio sobre a Africa descolonizada. Trad. Narrativa Traçada. Luanda; Ramada: Mulemba; Pedago, 2014. p. 31.

20 MBEMBE, Achille. Sair da grande noite. Ensaio sobre a África descolonizada. Trad. Narrativa Traçada. Luanda; Ramada: Mulemba Pedago, 2014. p. 32.

${ }_{21}$ MBEMBE, Achille. Sair da grande noite. Ensaio sobre a África descolonizada. Trad. Narrativa Traçada. Luanda; Ramada: Mulemba; Pedago, 2014. p. 36
} 
ção colonial, torna-se, pois, enigma ou parábola de uma situação histórica - situação fantasmática que iniciara, que instruíra o filósofo, por meio dos cânticos e das lamentações da mãe de seu tio, sua avó, instruíra-o nos vestígios do desaparecimento, nos ecos dos "rastros de um homem desaparecido, cuja memória soterrada sob os escombros das proibições e das censuras do Estado, fora escrita foneticamente".22 Aparecimento, emudecimento e ecos conduzem-me às ficções brasileiras e latino-americanas que se envolvem com a memória dos desaparecidos pela Operação Condor, ditatorial, terrorista e genocida, levada à cabo na segunda metade do século XX, e que lidam justamente com a forma espectral, fantasmática, dos corpos de memória, com "os ecos das suas vozes emudecidas", cujas referências são inúmeras e cujas consequências trágicas também, ainda hoje visiveis invisiveis, reproduzem-se sem cessar. Mbembe, rememorando e analisando a sua passagem por Paris e Nova lorque, nesse mesmo livro, se pergunta, irônica e tragicamente: "será necessário frisar que não me esqueço de que, nessa mesma metrópole [NY], um negro pode ser crivado de quarenta balas pela polícia apenas por estar no lugar errado à hora errada?"23 Seria preciso dizer oitenta balas? Cento e vinte balas? Lidar com os espectros. Com a sua brumosa qualidade fisionômica. Com a transitoriedade, no sentido de Vergänglichkeit, deperecimento, ruinância aquém do presente indicativo, portanto, fora do controle arquiontológico da presença jungida ao que provém "vom je-weilig Anwesenden",24 a cada momento, estado, estada, presente a si para si. Lidar à maneira de um fantasma contra o status quo, "conferir à sepultura toda a sua força subversiva".25 E desmontar, nesse sentido, desarmar as dimensões ontológicas das quais decorrem a fabricação dos sujeitos raciais, a partir das artifi- cialidades levadas a cabo fisicamente, materialmente empreendidas, realizadas contra outrem de fato, consolidadas por operações que são ao mesmo tempo do imaginário e das baionetas e dos navios e troncos e chicotes, articulando aparência, verdade e simulacro, a raça, o racismo e a colonização, o capitalismo, a escravidão e o fascismo consubstanciando-se assim nas formas de estabelecer e afirmar o exercício de um poder ancorado em forças pulsionais. Desmontar isso. - "Pour qu'elle puisse opérer en tant qu'affect, pulsion et speculum, la race doit se faire image, forme, surface, figure et surtout structure imaginaire"26 - porque a raça, para que possa operar como afeto, pulsão e espelho, speculum, como refere Mbembe, deve se fazer imagem, forma, superficie e figura, brutalmente sobredeterminadas, a raça deve sobretudo fazer funcionar uma estrutura imaginária: "la logique de l'enclos", ${ }^{27}$ a lógica de curral, a qual supõe tanto um elevado grau de bio e necrotecnologia de governo, quanto de estupidez, de barbárie, ódio e idiotia. E o negro sequestrado, escravizado, torturado representa, contudo, uma figura problemática, uma imagem perturbadora da- e para a modernidade e contemporaneidade, quer dizer, "en tant qu'esclave, le Nègre représente donc l'une des figures troublantes de notre modernité, dont il constitue au demeurant la part d'ombre, la part de mystère et la part de scandale",28 o negro "representa", portanto, em sentido crítico, estético e político, não obstante todas as extremidades do "irrepresentável", dos curto-circuito da representação que terão encarnado, escancarado, escancarnado em seu corpo, as chances de narrar o sofrimento desde uma forma sensivel impar, configurando-se enquanto humanidade subalterna, transfigurando-se enquanto devir subalterno do mundo, conformando, desconformando e desconfortando a

\footnotetext{
22 MBEMBE, Achille. Sair da grande noite. Ensaio sobre a África descolonizada. Trad. Narrativa Traçada. Luanda; Ramada: Mulemba: Pedago, 2014. p. 37.

${ }_{23}$ MBEMBE, Achille. Sair da grande noite. Ensaio sobre a África descolonizada. Trad. Narrativa Traçada. Luanda; Ramada: Mulemba: Pedago, 2014. p. 42

24 DERRIDA, Jacques. Spectres de Marx. L'État de la dette, le travail du deuil et la nouvelle Internationale. Paris: Galilée, 1993. p. 50.

25 MBEMBE, Achille. Sair da grande noite. Ensaio sobre a África descolonizada. Trad. Narrativa Traçada. Luanda; Ramada: Mulemba;

Pedago, 2014. p. 48.

26 MBEMBE, A. Critique de la raison nègre. Paris: La Découverte, 2013. p. 57

27 MBEMBE, A. Critique de la raison nègre. Paris: La Découverte, 2013. p. 62

28 MBEMBE, A. Critique de la raison nègre. Paris: La Découverte, 2013. p. 63
} 
parte sombria deste mundo, de mistério e de escândalo, seja porque as suas capacidades de descendência e geração foram barradas e borradas de várias formas, esterilizadas, anestesiadas, definhadas e deturpadas, seja porque faz figura nele, nela, o rosto desfigurado do agora, transfigurado, o rosto do trabalho espoliado - na palavras de Mbembe, "le pouvoir de descendance et de génération brouillé, le visage défiguré et le travail spolié, il témoigne d'une humanité mutilée, profondément marquée au fer de l'aliénation"29 - quer dizer, o negro, a negra testemunham pela parte da humanidade mutilada, marcada a ferro pela alienação, e, por isso, assombram a modernidade e a modernidade tardia justamente em virtude das possibilidades insurrecionais radicais que o seu testemunho carrega consigo, a memória do futuro, o futuro do pretérito da libertação, a libertação do jugo e do jogo ontológico de uma sociedade, a nossa sociedade: ocidental, capitalista, colonialista, racista, cuja abstrata-concreta consistência depende injustamente da subjugação de outrem.

Cito fragmentos escritos por Carolina Maria de Jesus, em Quarto de despejo:

Estendi as roupas rapidamente e fui catar papel. Que suplicio catar papel atualmente! Tenho que levar a minha filha Vera Eunice. Ela está com dois anos, e não gosta de ficar em casa. Eu ponho o saco na cabeça e levo-a nos braços. Suporto o peso do saco na cabeça e o peso da Vera Eunice nos braços. Tem hora que revolto-me. Depois domino-me. Ela não tem culpa de estar no mundo ${ }^{30}$. [...] Os políticos sabem que eu sou poetisa. E que o poeta enfrenta a morte quando vê seu povo oprimido. [...] Eu ontem comi aquele macarrão do lixo com receio de morrer ${ }^{31}$. [...] Os favelados aos poucos estão se convencendo que para viver precisam imitar os corvos ${ }^{32}$. [...] É horrivel ter só ar dentro do estômago ${ }^{33}$. E assim no dia 13 de maio de 1958 eu lutava contra a escravatura atual - a fome! ${ }^{34}$ [...] Fui na sapataria retirar os papeis. Um sapateiro perguntou-me se o meu livro é comunista. Respondi que é realista. Ele disse-me que não é aconselhável escrever a realidade. [...] Eu estava pagando o sapateiro e conversando com um preto que estava lendo um jornal. Ele estava revoltado com um guarda civil que espancou um preto e amarrou numa árvore. O guarda civil é branco. [...] Quem sabe se guarda civil ignora que já foi extinta a escravidão e ainda estamos no regime da chibata?.35

Ora, Mbembe aponta para às cascas, às carcaças, às sobras do corpo do escravo negro depois de destrinchado ou descarnado. Disjuntado à extensão dos destroços. Os quais, ao aparecerem, transparecerem, tornam-se enigmas, fantasias, fantasmas. Apparition: surgimento na ficção dos destroços do ente, os fragmentos do não-ente, insurgindo subitamente disjuntos, precariamente jungidos, ligados às afinidades e desafinidades que apontam para o trânsito entre a realidade e a irrealidade da imago e entre esta e a realidade de um conteúdo histórico latente ou emergente, sem que seja possivel entrar na posse intransitiva do que é ou seria o seu éter, a sua quinta-essência, o seu firmamento. O nome negro, negra, remete, assim, a uma fantasmagoria, diz Mbembe: "le mot 'Nègre' renvoie donc à une fantasmagorie". ${ }^{36} \mathrm{E}$ sofrem uma tripla lógica de ossificação sob esse nome, determinadas pessoas, e o mundo também. Lembro de novo o que escreveu Carolina Maria de Jesus: "passei no frigorifico, peguei uns ossos. As mulheres vasculham o lixo procurando carne para comer. E elas dizem que é para os cachorros. Até eu digo que é para os cachorros". ${ }^{37}$ - E, obviamente, não importam as leis, os principios, os valores, ou importam demasiado, como sabemos. O ordenamento juridico político capital policial pode vir à tona ou não, implícita ou explicitamente, nas ficções no subsolo da crítica da razão negra. Aparência e execução, metáfora e realização; essência; ciência; violência, perversão e exceção, ancorados no fundo do ser. Biologia, psicologia e antropologia e filosofia arregimentadas para comporem um pano de fundo muito bem determinado pelas filosofias existenciais.

\footnotetext{
MBEMBE, A. Critique de la raison nègre. Paris: La Découverte, 2013. p. 64. JESUS, Carolina Maria de. Quarto de despejo. São Paulo: Ática, 2005. p. 19. JESUS, Carolina Maria de. Quarto de despejo. São Paulo: Ática, 2005. p. 35. JESUS, Carolina Maria de. Quarto de despejo. São Paulo: Ática, 2005. p. 37. JESUS, Carolina Maria de. Quarto de despejo. São Paulo: Ática, 2005. p. 39 JESUS, Carolina Maria de. Quarto de despejo. São Paulo: Ática, 2005. p. 27. JESUS, Carolina Maria de. Quarto de despejo. São Paulo: Ática, 2005. p. 96 MBEMBE, A. Critique de la raison nègre. Paris: La Découverte, 2013. p. 67.

JESUS, Carolina Maria de. Quarto de despejo. São Paulo: Ática, 2005. p. 94
} 
O pano de fundo da cova. Um véu, um vínculo ensanguentado: a perene relação entre a morte e os negócios e o Estado e o direito, repetida ad infinitum por espécies de pedagogias da naturalização, a naturalização tornada construção de uma ideia por sobre o que for, não for - "le prototype du sujet empoisonné et carbonize",38 envenenado, carbonizado, sujeito prototípico, negro, negra, cuja vida é feita de "débris calciné", residuos calcinados, uma "deuxième ontologie", segunda ontologia, "segunda natureza", se usarmos os termos de Hegel e Lukács e Adorno e Benjamin, uma chaga, ferida viva, corrosão da vida vivida não vivida, subtraida, "un chancre une blessure vive, qui ronge, dévore et détruit",39 escreveu Mbembe - "eine Schädelstätte vermoderter Innerlichkeiten", 40 como apontou Lukács, um ossuário de interioridades putrefatas, um espaço, um estado tal do crânio, da carcaça, do calvário, cujas estruturas foram construidas e justificadas pelos homens, assim como o conteúdo sedimentado de suas leis - estruturas nas quais, sobre ou sob as quais apenas aparentemente vivemos, sobrevivemos às consequências dessa naturalização da história, das forças, dos poderes e das potências históricas, que procuram, que desejam conduzir ao anestesiamento, conduzir à anestética, ${ }^{41}$ cuja forma neutraliza ontologicamente, portanto, efetivamente, o conhecimento do poder e do Estado e do direito e do exercício conjunto, racista, escravocrata e genocida das suas forças. - E então, pergunta-se um senhor ao passar, parar e olhar uma reunião de indigentes no dia 24 de dezembro, em São Paulo: "será que este povo é deste mundo?"42, como escreveu Carolina Maira de Jesus: "eu achei graça e respondi: nós somos feios e mal vestidos, mas somos deste mundo. Passei o olhar naquele povo para ver se apresentava aspecto humano ou aspecto de fantasma". 43 Mas as entradas para o subsolo da crítica da razão negra são múltiplas, exigem que nos demoremos pelas suas veias. A razão mercantil governamental, as suas leis, juridicas e morais e biológicas, armas das guerras imperiais, nacionais, coloniais fazem figura orgulhosa na linguagem da conquista e da dominação e do terror, mascaram os vínculos entre derramamento de sangue, a desnutrição programada e a ordem biológica e jurídica aqui e acolá, enevoam a naturalização a expropriação de outrem seja por vias aristocráticas, oligárquicas ou "democráticas", elas mesmas aparentes - jamais esqueçamos o tráfico atlântico e o genocídio indígena e as desaparições forçadas - a razão mercantil governamental que destina à destruição os desgraçados destroços que são os corpos-objetos sujeitos-raciais. À razão da destruição de outrem, pois, confluem, arregimentadas, filosofias, políticas e um imaginário convicto, junto aos quais, de acordo com os quais, a "África" tornou-se, em sentido torturante, um inesgotável, inaterrisável, infindável poço de fantasias, "un intarissable puits aux fantasmes", 44 fantasias da destruição cabal do outro, fantasia da totalidade ao mesmo tempo concreta, assassina: outrem destruido. Fantasia de totalidade decerto levada a cabo, velada, não velada, ao fim do qual não-aí, a putrefação. A segunda ontologia. Aparência de necessidade eterna e imutável e fora do alcance humano. Espetáculo da dissociação, do desmembramento, da degradação do outro, plenamente justificada por uma razão de ser de origem, regendo uma lógica da identidade e uma linguagem da autenticidade humana e racial, com as quais se empenhavam os senhores, em suas formas atrozes de invocar a diferença, e cuja filosofia tornou-se nada mais do que consentimento à escravidão ${ }^{45}$, a filosofia do terror. - Mas emergem fantasias outras, contudo, para além da funcionalização do terror. O trabalho com a memória, entendido

38 MBEMBE, A. Critique de la raison nègre. Paris: La Découverte, 2013. p. 67.

39 MBEMBE, A. Critique de la raison nègre. Paris: La Découverte, 2013. p. 67.

40 LUKȦCS, Georg. Die theorie des Romans. Ein geschichtsphilosophischer Versuch über die Formen der großen Epik. Darmstadt: Neuwied: Luchterhand, 1984. p. 55.

${ }_{41}$ Cf. BUCK-MORSS, Susan. Aesthetics and Anaesthetics: Walter Benjamin's Artwork Essay Reconsidered. October, v. 62, Autumn, 1992. p. 3-41.

42 JESUS, Carolina Maria de. Quarto de despejo. São Paulo: Ática, 2005. p. 128

43 JESUS, Carolina Maria de. Quarto de despejo. São Paulo: Ática, 2005. p. 128

44 MBEMBE, A. Critique de la raison nègre. Paris: La Découverte, 2013. p. 109.

45 MBEMBE, A. Critique de la raison nègre. Paris: La Découverte, 2013. p. 141. 
como um trabalho fantasmático, "un entrelacs d'images psychiques", 46 complexos representacionais, enérgicos, literalmente um entrelace de imagens psíquicas tal como levadas a cabo no tempo do sonho, no tempo da fantasia. O tempo de uma aparição ou de uma reaparição perdida ou da sua desaparição, fora de todo pacto com o presente centrado em termos contratuais para trair o futuro - o entrelaçamento do tempo da crítica do tempo, através da forma não previamente dada ou preestabelecida, procura lidar com- e analisar o acontecimento, a construção e a desconstrução da memória das plantations, bem como da sua manutenção por vias transversas, lidar com a memória da escravidão negra, da colonização e do tráfico de pessoas. E, então, "ceci dit, il reste que faire mémoire de la colonie, ce n'est pas seulement s'engager dans un travail psychique" - quer dizer, dito isto, o trabalho com a memória da colônia (escravidão, massacres e desaparecimentos) não está engajado apenas numa forma de trabalho psíquico ou psicanalítico - "c'est aussi opérer une critique du temps et des artefacts qui ont prétention à être les substituts derniers de la substance même du temps"47 - mas também opera, no sentido filosófico do termo, uma crítica do tempo e dos artefatos que pretendem, que ambicionam, que fingem ser os substitutos últimos do tempo, da substância, do substrato mesmo do tempo, sempre às custas das vidas de outrem. O trabalho literário, o trabalho corpo-ficcional com a linguagem e a memória e com o tempo evidencia, antes, a disjunção do tempo com o tempo dado: o tempo disjunto ao ser, a ver ou haver outrem tão somente como relâmpagos, como iluminações.

Cito Lima Barreto, no Diário do hospício, incluido no Cemitério dos vivos:

Amaciando um pouco, tirando dele a brutalidade do acorrentamento, das surras, a superstição de rezas, exorcismo, bruxarias etc., o nosso sistema de tratamento da loucura ainda é o da Idade Média: o sequestro. Não há dinheiro que evite a morte, quando ela tenha de vir; e não há dinheiro nem poder que arrebate um homem da loucura. Aqui no Hospício, com as suas divisões de classes, de vestuário etc., eu só vejo um cemitério: uns estão de carneiro e outros de cova rasa. Mas, assim e assado, a loucura zomba de todas as vaidades e mergulha todos no insondável mar de seus caprichos incompreensiveis. ${ }^{48}$

O subsolo da crítica da razão negra apenas aparentemente adquire um estatuto ontológico, apenas na medida em que o trabalho da filosofia do ser do ente funcionaliza os rituais da repetição e da identidade e, de acordo com isso, escamoteia os encantos dos destroços e da destruição e da habituação à morte de outrem, levados a cabo por agências e agentes os mais diversos no curso histórico da colonização e da escravidão, empreendidos desde o fascínio da ideia de algo absolutamente primeiro e uno e autêntico, de destino promissor derradeiro, por meio de uma "realidade" plenamente racionalizada e administrada e justificada em função disso, quer dizer, apenas no logro de uma realidade sancionada como inalterável - a fatalidade do encantamento, do encadeamento e do encarceramento justificados por si mesmos para o outro - a organização da vida para a morte cumpre a promessa atemporal da presença a si mesma, para a qual nem a pobreza, nem a indigência ou a miséria devem de fato desaparecer. Mas as ontologias da falsa consciência, por vias transversas, não logram mais evitar a confissão das manias de totalidade que transbordam de suas sentenças, subsumindo à fatalidade as evidências dos mecanismos de massacres e colonização que se perpetuam no tempo da existência maltratada e devastada. $E$ isso quer dizer que, apenas de modo sequestrado e para além de toda consolação encontra-se o subsolo da crítica da razão negra sob a égide de um regime ontológico, cujos poderes existenciais derivam da "convicção de que a destruição do próprio corpo não afeta a continuidade do ser". 49 Essencialmente, um tal subsolo não se encontra na abertura de uma cova, de uma vala, num cemitério ou hospício; numa prisão,

\footnotetext{
MBEMBE, A. Critique de la raison nègre. Paris: La Découverte, 2013. p. 154.

MBEMBE, A. Critique de la raison nègre. Paris: La Découverte, 2013. p. 154.

BARRETO, Lima. O cemitério dos vivos. São Paulo; Rio de Janeiro: Editora Planeta; Fundação Biblioteca Nacional, 2004. p. 69.

MBEMBE, Achille. Necropolitica. Trad. Renata Santini.São Paulo: n-1 Ed., 2018. p. 68.
} 
numa favela ou num quarto de despejo; as tentativas levadas a cabo pelas filosofias justificadoras da existência racista, capitalista e fascista, de colonizar o imaginário e determinar as virtualidades da existência apodrecida, acabam sendo enfrentadas justamente através da extrapolação dos limites circunscritos por um lugar específico, aparentemente desconectado do curso do mundo, um curral de arame farpado muito bem determinado - esses locis de linguagem, extrapolam inclusive os limites das suas propriedades especíicas e se deixam apresentar, antes, como trincheiras da imaginação e da fantasia não predeterminada - contra as necessidades e consequências de séculos de colonização e escravidão e terrorismo de Estado, instrumentalizados pela primazia do ser e pela justificação da existência a despeito dos corpos fantasmáticos de linguagem e das sombras personificadas ou despersonificadas nos manicômios e nas prisões e favelas e valas da modernidade tardia, porque tais tornam-se as materialidades arquitetônicas que abrigam o exercício de uma violência atroz: a sintese entre a burocracia e o massacre. "Na realidade, a ligação entre a modernidade e o terror", 50 o que quer dizer também a fusão entre razão e terror, que serviu e serve para "marcar a aberração no corpo político"51 - "reduzir o outro e a si mesmo ao estatuto de pedaços de carnes inertes".52 Ora, na passagem do ano 1919 para o 1920, internado pela segunda vez no Hospital Nacional dos Alienados, Lima Barreto escreveu o Diário do hospício, texto que se tornou a base para o romance inacabado Cemitério dos vivos, uma reelaboração, uma perlaboração estética do tema da loucura e da razão e do sofrimento social, da escrita mesma e de seus deslocamentos de sentidos entre o hospício e o cemitério - apenas publicada cerca de trinta anos depois da morte do escritor, configurando-se, pois, nisso, também uma sua situação fantasmática. Nesse romance, os seus leitores se deparam com as indiscerniveis asperezas que concernem às junções e disjunções da "realidade" e da "ficção", cujos limiares abordam-se, abeiram-se, ao controle da diferença lógica e metodologicamente estabelecida, bem como ao descontrole do gênero indeterminado da escrita, cruzando, transparecendo ficção e não ficção, às margens de alucinações visuais, da visão de bichos pelas paredes, outros bichos pelos colchões, pulgas, baratas e percevejos que viravam monstros e que davam vazão, para o seu autor, aos piores temores frente à realidade, quando em crise ${ }^{53}$ - a realidade que não podemos entender como acomodada a si mesma no Cemitério dos vivos, acomodada sob um determinado regime de visibilidade aí, sob a égide do simulacro, no romance, essas alucinações não precisam transparecer como imagens. E nesse sentido a forma torna-se um elemento crucial do Cemitério. E o governo da vida, para a vida e para a morte, e suas tratativas para o controle do tempo que resta, no Diário do hospício e no Cemitério dos vivos, deixam transparecer os procederes e os pormenores críticos de uma situação social como se fossem contados pela pena de um etnógrafo, muitas vezes bem próximo da fantasmaterialidade com a qual nos deparamos ao ler o Quarto de despejo - cujas letras e imagens trazem à tona em ambas as ficções, apresentam, aquilo que apenas aparentemente pode ser tratado por realista. O fantástico, realista no mais alto grau, como em Uma criatura dócil, propôs Dostoievski, ${ }^{54}$ tão admirado por Lima Barreto. ${ }^{55} \mathrm{O}$ jogo dos traços, das sombras e dos espectros da literatura, perigosamente articulados e posicionados contra o status quo; contra a conivência e a conveniência de uma República recém fundada sob os ideais de um positivismo racista e eugenista; contra as consequências disso na miséria e desamparo sociais ao longo de todo o século XX - tal jogo de sombras e espectros de

\footnotetext{
MBEMBE, Achille. Necropolitica. Trad. Renata Santini.São Paulo: n-1 Ed., 2018. p. 21.

MBEMBE, Achille. Necropolitica. Trad. Renata Santini.São Paulo: n-1 Ed., 2018. p. 23.

MBEMBE, Achille. Necropolitica. Trad. Renata Santini.São Paulo: n-1 Ed., 2018. p. 64

SCHWARCZ, Lilia Moritz. Lima Barreto - Triste visionário. São Paulo: Companhia das Letras, 2017. p. 591 (ebook).

DOSTOIÉVSKI, Fiódor Mikhailovitch. Uma criatura dócil: narrativa fantástica. Trad. Fátima Bianchi. São Paulo: Cosac \& Naify, 2003. p. 7.

SCHWARCZ, Lilia Moritz. Lima Barreto - Triste visionário. São Paulo: Companhia das Letras, 2017. p. 603 (ebook). "O cemitério dos vivos seria um livro em diálogo com sua própria experiência e com a literatura de Dostoiévski. Mostraria também outro "subsolo" da nossa sociedade: o manicômio".
} 
letras e vidas deixam a escrita de Lima Barreto, bem como a de Maria de Jesus, expressar a herança, a memória, o legado de um número infinito de homens e mulheres, o "sentimento de estar enterrado e excluído daquela República",56 especialmente apanhados e enterrados - sequestrados, capturados, fora, incluidos pela exclusão no funcionamento do estado de exceção tornado a regra da sociedade patriarcal, oligárquica e racista. - Conta o narrador do Cemitério dos vivos, Vicente Macarenhas, caracterizado como preto, pobre, que abandonou a Escola Politécnica para trabalhar no Estado, que escreve numa revista humoristica e se endivida para publicar seus livros, conta ele que, "devido à pigmentação negra de uma grande parte dos doentes ai recolhidos [no hospício Nacional], a imagem que se fica é que tudo é negro. [...] [E] contemplando uma porção de corpos negros nus, faz ela que as outras se ofusquem no nosso pensamento".57 Ora, para além da circunscrição de espaço-tempo cercados no hospício Nacional e suas "paredes inexpugnáveis", o Cemitério dos vivos trata do baralhamento da morte pela morte levada a cabo em vida, da vergonha e da abjeção, da depressão e dissociação forçadas a outrem, o "pária social" - técnicas e mais técnicas de controle, formação de um tipo bio-psíquico-social, sujeito-objeto docilizado: muitas vezes jovens, "sem moléstia comum, que não falam, que não se erguem da cama nem para exercer as mais tirânicas e baixas exigências da nossa natureza, que se urinam, se rebolcam no próprio excremento". 58 No cemitério dos vivos, subsolo da sociedade brasileira oligárquica e racista, a "diferença" tornada degeneração segue o curso de um grande movimento histórico, o movimento da autenticidade, por razão de ser do qual operam a originariedade e a degenerescência funções racializadas, bestializado o outro, por meio de racionalizações e explicações acerca de uma sua hereditariedade, biológica, psicológica ou sociologicamente entendidas, a operação lógica da autenticidade soube confinar toda alteridade numa particularidade ontológica com a qual a governabilidade administra, até hoje, não apenas os seus enunciados abstratos, mas também, as vidas mesmas, as mortes e os corpos a ela submetidos. E a aparência da ficção crua, carne, choque e chicote, contudo, não precisa tornar-se evidente no Diário, nem no Cemitério, não é necessário dar a ver a imagem do tronco ou do estupro ou da lobotomia, conformes a história das estruturas raciais, para as quais as togas, os braceletes e os aventais prestam sempre grandes serviços, sevícias. - Lembro de uma cena: quando se encontrou sob os cuidados de um determinado médico, no hospício, o narrador do Cemitério, percebendo sua condição de desgraçado em mãos tão inquietas e sôfregas, sabia, então, que "tinha perdido toda a proteção social, todo o direito sobre o meu próprio corpo", diz, "era assim como um cadáver de anfiteatro de anatomia [...] à espera de ser vítima desse vício mental dos nossos métodos"59. E, diante disso, toda uma vasta necrópole resta, subterrânea, esperando a escavação da história da loucura no Brasil senhoril. Além disso, "o médico que tem em sua frente um doente, de que a polícia é o tutor e a impersonalidade da lei, curador" - como era o caso de Mascarenhas - "por melhor que seja [o médico], não o tem [o doente] na conta de gente, é um náufrago, um rebotalho da sociedade"60, um indigente.- Dai cruzam-se fragmentos provisórios, excedentes, como diz Mbembe, "les miroitements du réel", ${ }^{1}$ cintilações, brilhos tremeluzidos do real - o qual se compõe de muitas camadas, estratos, vias, véus, invólucros, nem tanto conforme, mais desconforme à segunda natureza aí petrificada à imago, seja na superficie ou no subsolo desta, dispersivas e ambiguas imagens, "igualmente representáveis", 62 nos ter-

\footnotetext{
SCHWARCZ, Lilia Moritz. Lima Barreto - Triste visionário. São Paulo: Companhia das Letras, 2017. p. 592 (ebook).

BARRETO, Lima. O cemitério dos vivos. São Paulo; Rio de Janeiro: Editora Planeta; Fundação Biblioteca Nacional, 2004. p. 188

BARRETO, Lima. O cemitério dos vivos. São Paulo; Rio de Janeiro: Editora Planeta; Fundação Biblioteca Nacional, 2004. p. 189.

BARRETO, Lima. O cemitério dos vivos. São Paulo; Rio de Janeiro: Editora Planeta; Fundação Biblioteca Nacional, 2004. p. 230.

BARRETO, Lima. O cemitério dos vivos. São Paulo; Rio de Janeiro: Editora Planeta; Fundação Biblioteca Nacional, 2004. p. 229.

MBEMBE, A. Critique de la raison nègre. Paris: La Découverte, 2013. p. 193.

RANCIĖRE, Jacques. O destino das imagens. Trad. Mônica Costa Netto. Rio de Janeiro: Contraponto, 2012. p. 131.
} 
mos de Rancière - transfiguradas no Cemitério dos vivos e no Quarto de despejo desde a figuração ruinante dos sujeitos em questão, em fabricação, não heróis, nem senhor, nem senhora, nem bem ordenado ou ordenhado na regulação das conveniências miméticas, adaptativas, indiciando com isso, pois, a própria "a derrocada do sistema representativo" de visibilidade e organização de uma forma hierárquica de olhar, estética e historicamente falando ${ }^{63}$. Uma face, um torso destroçado, um sonho para as ruínas do regime da proporção, oferecem, pois, tanto o Cemitério dos vivos quanto o Quarto de despejo. E inúmeros aspectos históricos entrecruzam-se em imagens à aparência de ser, não ser, desfazer, aquela que se encontra transfigurada nas letras - a figura trans da imago - "au seuil du monde visible"64, no limiar do mundo visivel, ambíguo, sombrio, a treva absoluta do racismo, do capitalismo e das novas formas de escravidão. Mascarenhas, instruído, educado, honesto, procurando uma vida pura, gostaria de estar a coberto de toda a desonra, muito longe de toda abjeção, mas não como escreveu, "eu e a sorte, a sorte e eu, nos juntamos de tal sorte, nos irmanamos, que vim a passar por transes desses", o autor das memórias, "caindo de sonho em sonho"65, passou, teve que passar por transes, agonias amargas, consternações. Mas a superficie do visivel do romance pouco informa de fato a respeito dos seus sonhos ou do mundo de silhuetas dos seus transes, dos seus delírios, a respeito do seu mundo de duplos, de convulsões de sentimentos; só o desgosto catalisado pela experiência de uma doença, pelo "espetáculo da loucura" e pela aparência própria imprópria dele mesmo, um regressado do cemitério dos vivos. - "Digo com franqueza, cem anos que viva eu, nunca poderão apagar-me da minha memória essas humilhações que sofri"66. Porque as vidas sombrias e fantasmáticas não foram criadas e oferecidas ao léu - o véu do ser - por imagens de pensamentos, empunhadas na forma, a escrita, seja no Cemitério dos vivos, seja no Quarto de despejo, antes, terão surgido em torno a nós outros, leitores, como num cruzamento úmido, temporal e subterrâneo, labirintico: o cemitério em comum, o despejo em comum, nos quais apenas transitoriamente nos encontramos, tal como num depósito de reminiscências ou em narrativas caseiras: vestígio de uma ocasião, um corpo de linguagem capaz de escapar do sequestro real e fantástico operado pelo ser. - A força da loucura, escreveu Lima Barreto, encontra assim as suas pretensões literárias ${ }^{67}$ lançadas aos mistérios da degradação, da miséria e da humilhação humanas, no círculo do inferno da existência dada e plenamente justificada.

Do Cemitério dos vivos:

O espetáculo da loucura, não só no individuo isolado, mas, e sobretudo, numa população de manicômio, é dos mais dolorosos e tristes espetáculos que se pode oferecer a quem ligeiramente meditar sobre ele. Dizia Catão que os sábios tiram mais ensinamentos dos loucos que estes deles. Deve ser assim, conforme quem os interpela e o tempo que o faz, mas o certo é que, à primeira vista, o ensinamento não é, como queria o orgulho romano, para melhoramento e progresso dos ajuizados; ao contrário, a primeira impressão é de abjeção para o seu espírito, pelo enigma que nele se põe, diante de uma misteriosa interrogação sem resposta. Donde vem isto? Que inimigo da nossa espécie é esse que se compraz em nos rebaixar? ${ }^{68}$

\section{Do Quarto de despejo:}

Hoje não temos nada para comer. Queria
convidar os filhos para suicidar-nos. Desisti.
Olhei meus filhos e fiquei com dó. Eles estão
cheios de vida. Quem vive, precisa comer. [...]
Os lixeiros já haviam passado. Catei pouco
papel. Passei na fabrica para catar estopas.
Comecei a sentir tontura. Resolvi ir na casa
de Dona Angelina pedir um pouco de café. [...]
Já emagreci 8 quilos. Eu não tenho carne, e o
pouco que tenho desaparece. Peguei os papeis
e sai. Quando passei diante de uma vitrine vi
o meu reflexo: desviei o olhar, porque tinha
a impressão de estar vendo um fantasma. ${ }^{69}$ 
Arrastado pela literatura e pela fatalidade das palavras e das imagens com elas criadas para expressar ou apresentar o subsolo, a ruína e a destruição que continuamos a experimentar visceralmente, recordo que Frantz Fanon reivindicava justamente uma "tomada posição diante da linguagem"70 para que a luta contra o racismo e a razão negra, a combinação de volúpia, frenesi e crueldade, corpo e espelho fantasmáticos no interior de uma economia das sombras, pudesse levar a cabo a desconstrução do logos e seu modus operandi, como escreveu Mbembe, "une déconstruction généralisée de l'existence",71 desconstrução generalizada da existência diante da qual se trata de "réveiller les puissances endormies",72 pois, de despertar - despertar as potências adormecidas da insurgência, da insurreição, da imaginação, da crítica contra um estado de coisas ele mesmo espantoso por excelência. E a memória adquire, nesse vasto âmbito, no subsolo de um tempo atroz, um sentido crucial. Uma crítica do tempo desde fora do sentido hegemônico da presença. Desarmonizando, descentralizando, desarmando o império do sujeito colonial. O trabalho da memória, desde o subsolo da crítica da razão negra: relembrar, criar, enunciar à margem do que foi, o terá sido - isso ganha os ares de um trabalho psiquico, "les allures d'un travail psychique",73 frente às faces de linguagens esculpidas pela dor e pelo sofrimento inauditos, transformados em espectros fantasmagóricos, mirados apenas pela parca luz do desespero, agora, a consciência viva de uma situação social imprópria encontra a inconsciente fantasmático das ruinas. Inapaziguável expressão sensivel. Segundo escreveu Mbembe, "témoigner en situation coloniale, c'est avant tout rendre compte de vies plongées dans une interminable agonie", testemunhar a situação colonial se torna, antes de tudo, prestar conta às vidas mergulhadas, submergidas, afundadas, naufragadas numa interminável agonia. Além do quê, afirmou o filósofo que Fanon muito cedo se convencera de que toda a situação colonial era uma força fundamentalmente necropolítica, animada por uma pulsão genocida, "une situation de violence potentiellement exterminatrice qui, pour se reproduire et se perpétuer, devait pouvoir être convertie en une ontologie et en une génétique"74 - uma situação de uma violência potencialmente exterminadora, a qual, para se reproduzir e assim se perpetuar deveria ser conversivel numa ontologia e numa genética, o que quer dizer, antes, uma violência exterminadora que já se encontrava, de fato, retroanimada, retroalimentada por uma filosofia do terror e suas razões ontológicas, suas razões genocidas, facilmente capazes de travestir-se em genética. Contudo, a elaboração literária ficcional consiste em extrapolar os limites do exprimivel dentro dos esquadros de uma razão determinada para a manutenção existencial do horror, apontando expressivamente para os vestígios deixados disjuntos ao tempo da presença a si mesma, os vestígios da fantasmaterialmente deixados pelos corpos de memórias, corpos de linguagens e de imagens e acontecimentos não meramente passados, acontecidos, mas por acontecer. Nesse sentido, o ponto de partida das posições contracolonialistas e antirracistas "não é a questão do ser, mas a da relação e da composição"75, as quais só fazem sentido se abrem caminhos outros para o futuro. A abertura de arquivos literários, jamais dada por satisfeita, torna a indicar que, no subsolo da crítica, as linguagens e imagens da memória insistem na crítica do tempo, em participar da disjunção do tempo, fora do controle anestésico anestético do tempo, sem saber seguramente onde ancorar em si mesmas as suas pretensões, participando, assim, na multiplicidade sensivel, nos fluxos de potencialidades - a um tempo criativas e destrutivas - tratando de eludir constantemente a permanência do colonialismo e do racismo que vigem para muito além da aparência da sua desaparição e cujo devir não se deixa compreender sem as possibilidades fáticas de torturar, violar e massacrar, sem a gestão

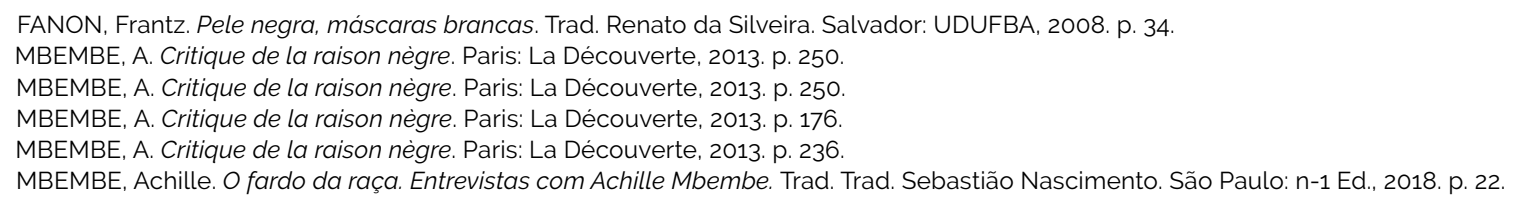


ontológica do terror, do encanto e da estupefação, com recursos biológicos, necrológicos, juridico-políticos e administrativos.

\section{Referências}

AB'SABER, Teles. Somos contemporâneos de nossa escravidão. São Paulo: n-1 Ed., 2018.

ADORNO, Theodor. Teoria estética. Trad. Artur Morão. Coimbra: Edições 70, 2008.

ASSIS, Joaquim Maria Machado de. Memórias póstumas de Brás Cubas. Porto Alegre: L\&PM Pocket, 1997.

AZEVEDO, José Fernando Peixoto de. Eu, um crioulo. São Paulo: n-1 Ed., 2018.

BARRETO, Lima. O cemitério dos vivos. São Paulo: Editora Planeta; Rio de Janeiro: Fundação Biblioteca Nacional, 2004.

BARRETO, Lima. Histórias e sonhos. Rio de Janeiro: Expressão e Cultura, 2001.

BENJAMIN, Walter. Einbahnstrasse. Berlin: Ernst Rowohlt Verlag, 1928.

BENJAMIN, Walter. Imagens de pensamento. Trad. João Barrento. Lisboa: Assírio \& Alvim, 2004.

BUCK-MORSS, Susan. Aesthetics and Anaesthetics: Walter Benjamin's Artwork Essay Reconsidered. October, Cambridge, Mass., US, v. 62, p. 3-41, Autumn, 1992. https://doi.org/10.2307/778700.

CÉSAIRE, Aimé. Discurso sobre o colonialismo. Trad. Noémia de Sousa. Lisboa: Sá da Costa Ed. 1978.

DERRIDA, Jacques. Spectres de Marx. L'État de la dette, le travail du deuil et la nouvelle Internationale. Paris: Galilée, 1993

DERRIDA, Jacques. Espectros de Marx: O Estado da divida, o trabalho do luto e a nova Internacional. Trad. Anamaria Skinner. Rio de Janeiro: Relume-Dumará, 1994.

DOSTOIÉVSKI, Fiódor Mikhailovitch. Uma criatura dócil: narrativa fantástica. Trad. Fátima Bianchi. São Paulo: Cosac \& Naify, 2003.

FANON, Frantz. Pele negra, máscaras brancas. Trad. Renato da Silveira. Salvador: UDUFBA, 2008. https:// doi.org/10.7476/9788523212148.

HEIDEGGER, M. A origem da obra de arte. Trad. Idalina Azevedo e Manuel de Castro. São Paulo: Edições 70, 2010.

JESUS, Carolina Maria de. Quarto de despejo. São Paulo: Ática, 2005

BIRMAN, Joel. Freud e a filosofia. Rio de Janeiro: Jorge Zahar, 2003.

GORDON, Lewis. Black Aesthetics, Black Value. Public Culture, Chicago, Ill., US, v. 30, n. 1, p. 19-34, Jan. 2018. https://doi.org/10.1215/08992363-4189143.
KRANIAUSKAS, John. Beware Mexican Ruins! 'One-Way Street' and the Colonial Unconscious. In: BENJAMIN, A.; OSBORNE, P. Walter Benjamin's Philosophy: Destruction and Experience. Londres: Routledge, 1994. p. 139-154.

LUKÁCS, Georg. Die theorie des Romans. Ein geschichtsphilosophischer Versuch über die Formen der großen Epik. Darmstadt: Luchterhand, 1984.

LUKÁCS, Georg. A teoria do romance: um ensaio histórico-filosófico sobre as formas da grande épica. Trad. José Marcos de Macedo. São Paulo: Duas Cidades: Ed. 34, 2000.

MBEMBE, Achille. As formas africanas da auto-inscrição. Trad. Patricia Farias. Estudos Afro-Asiáticos, Rio de Janeiro, v. 23, n. 1, p. 171-209, 2001. https://doi.org/10.1590/ S0101-546X2001000100007.

MBEMBE, Achille. Critique de la raison nègre. Paris: La Découverte, 2013.

MBEMBE, Achille. Crítica da razão negra. Trad. Sebastião Nascimento. São Paulo: n-1 Ed., 2018

MBEMBE, Achille. Necropolitica. Trad. Renata Santini. São Paulo: n-1 Ed., 2018.

MBEMBE, Achille. O fardo da raça: Entrevistas com Achille Mbembe. Trad. Trad. Sebastião Nascimento. São Paulo: n-1 Ed., 2018.

MBEMBE, Achille. Sair da grande noite. Ensaio sobre a África descolonizada. Trad. Narrativa Traçada. Luanda: Pedago, 2014

NANCY, Jean-Luc. Demanda: Literatura e filosofia. Trad João Camillo Penna et all. Florianópolis: EDUFSC: Argos, 2016.

PANDOLFO, Alexandre. Apuros: ficção e aforismas contra o estado das coisas. Porto Alegre: Lapices, 2017.

PINTO NETO, Moysés. A estranha instituição da literatura no multiverso dos espectros. ALEA, Rio de Janeiro, v. 17 , n. 1., p. 114-126, 2015. https://doi.org/10.1590/S1517106X2015000100008.

RANCIĖRE, Jacques. A partilha do sensivel. Trad. Mônica Costa Netto. São Paulo: Ed. 34, 2009.

RANCIĖRE, Jacques. O destino das imagens. Trad. Mônica Costa Netto. Rio de Janeiro: Contraponto, 2012.

RANCIĖRE, Jacques. O inconsciente estético. Trad. Mônica Costa Netto. São Paulo: Ed. 34, 2009.

SCHWARCZ, Lilia Moritz. Lima Barreto: Triste visionário. São Paulo: Companhia das Letras, 2017. E-book.

\section{Alexandre Costi Pandolfo}

Doutor em Letras pela Pontifícia Universidade Católica do Rio Grande do Sul (PUCRS), em Porto Alegre, RS, Brasil. Pós-doutor em Letras pela Universidade Federal de Pelotas (UFPel), em Pelotas, RS, Brasil. Pós-doutor em Literatura pela Universidade Federal de Santa Catarina (UFSC), Florianópolis, SC, Brasil. 


\section{Endereço para correspondência}

Alexandre Costi Pandolfo

Av. Caçapava, 272/502

Petrópolis, 90460130

Porto Alegre, RS, Brasil 